\title{
Confronting the Challenges of Graduate Education in Sub-Saharan Africa and Prospects for the Future
}

\author{
Fred M. Hayward and Daniel J. Ncayiyana
}

\begin{abstract}
This study examines the current status of graduate education in SubSaharan Africa. How has it been affected by the decline in donor funding, economic crises in much of Africa, the phenomenal growth in undergraduate education, and a shortage of faculty members with PhDs. One of the authors suggested in an earlier study that a short-term response to the shortage of high quality graduate education might be regional graduate centers. Has that taken place? To what extent has graduate education improved and expanded? Where has growth taken place? We explore challenges facing the development of high quality graduate education including those of recruitment and retention, efforts to improve the qualifications of faculty members, funding issues, as well as research and publications. Several innovative graduate programs are examined. Finally, we make recommendations for the growth and quality improvement of graduate education including rekindling a culture of research, a focus on quality teaching, and the critical need for major investments in high quality graduate education.

Cette analyse s'intéresse au statut des études de master et de doctorat en Afrique subsaharienne. Comment ont-elles été affectées

ABOUT THE AUTHORS: FRED M. HAYWARD is a specialist on higher education with more than 30 years of experience as an educator, scholar, senior administrator, and higher education consultant. He has written extensively on development issues in Africa and Asia. DANiEl J. NCAYIYANA is former Vice Chancellor of the Durban University of Technology and Deputy Vice Chancellor of the University of Cape Town. He is Editor-in-Chief of the South African Medical Journal and a higher education consultant. Address correspondence about this article to Fred M. Hayward, 3628 Van Ness St. NW, Washington DC. 20008, e-mail: haywardfred@hotmail.com.
\end{abstract}


par la diminution des dons financiers, les crises économiques dans toute l'Afrique, la croissance phénoménale du nombre d'étudiants en licence, et le manque de professeurs titulaires d'un doctorat? Un des auteurs a suggéré dans de précédents travaux une réponse à courtterme à la pénurie de diplômés de master et de doctorat d'excellent niveau : des centres régionaux consacrés aux études de masters et de doctorat. Ceci a t-il été mis en place ? Dans quelle mesure les formations de master et de doctorat se sont-elles améliorées et leur nombre a t-il augmenté ? Où la croissance a t-elle eu lieu ? Nous nous attardons sur les obstacles au développement de formations de master et de doctorat de qualité, en particulier ceux de recrutement et de rétention des étudiants, les efforts pour améliorer les qualifications des professeurs, la situation financière ainsi que la recherche et les publications. Plusieurs formations innovantes de master et de doctorat sont examinées. Finalement, nous proposons des recommandations pour la croissance et l'amélioration de la qualité des études de master et de doctorat, notamment raviver la culture de recherche, se concentrer sur la qualité de l'enseignement, et le besoin critique d'investissements majeurs dans des masters et doctorats de qualité.

\section{Introduction}

A few years ago one of the authors of this piece reviewed Africa graduate education and reported that it had been in decline from the I980s and that so was much of the continent's undergraduate education (Hayward, 20IO). That article also suggested that regional graduate education centers could be a short-term answer to the quality problem. To what extent has that happened? Have governments or donors moved to facilitate such a development? Have other factors helped improve graduate education over the last five years? What is the current status of graduate education in Africa? This article is an examination of whether the status of graduate education in Africa has improved and prospects for the future of African graduate education.

The situation in 2010 was particularly striking in contrast to the productivity, academic quality, and lively debate at a number of Africa's early universities including Fourah Bay College (I827), University of Cape Town (I829), Liberia College (I862), Makerere University (I922), University of Ghana (I948), and Ibadan University (I948). By the I96os and I970s in particular, these and many of the newer African universities, were flourishing. Teaching and research were of high quality, classes were small and student centered, discussion was prized, higher education generally was well supported by governments and donors, and many faculty members were active in policymaking, public service, and carrying out research focusing on the nation's critical problems. The universities were held in high esteem by citizens and politicians, graduates had little or no difficulty finding employment (mostly in government), and prospects for the future seemed bright. In many of these universities, the quality of academic life was on a par with some of the best universities in Europe, the United States, and the United Kingdom (Sawyerr, 2004).

Yet, by the mid-I97os both the environment for higher education and its status began to change in most of Sub-Saharan Africa. The economy was in crisis in many African countries, some governments had come to regard universities as bastions of unwelcome criticism and centers of opposition, costs seemed too high to many governments, faculty and student lifestyles came under question, and the utility of universities suddenly seemed limited. The economic crises faced by most governments were real and had very negative consequences for higher education funding. As the World Bank study Accelerating Catch-up documented some years later, "Over a 20 -year period extending from the mid-I970s to the mid-I99os per capita GDP growth in SSA [Sub-Saharan Africa] was either zero or negative" (World Bank, 2009a, p. 8). The loss of most World Bank, UNESCO, and other donor funding during this period was also a major contributor to the decline. Partly based on World Bank reports, these donors concluded that development efforts in Africa should concentrate on "education for all" socusing on primary education, rather than higher education. Funding dropped precipitously. Indeed, bank staff suggested that the problems of African higher education were largely a result of stagnation and deterioration in quality (World Bank, i988). Bank specialists had suggested at a meeting with African University Vice Chancellors in I986 that higher education in Africa was a luxury-that it might be better to close some institutions, or send those needing graduate work abroad (Brock-Utne, 2002, p. 8).

These World Bank conclusions were partly a result of work done by George Psacharopoulos and Patrinos (2004) at the bank on rate of return to investments in education. Their findings suggested that the rate of return from primary and secondary education was much higher than that from tertiary education. Those and related findings were to affect World Bank funding decisions for years. Some of the data were badly flawed, reflecting the small number of African university graduates at the time the data were gathered and the fact that many primary and secondary school graduates obtained relatively high positions (with

The Dakar Framework for Action mandated UNESCO to coordinate these partners, in cooperation with the four other conveners of the Dakar Forum (UNDP, UNFPA, UNICEF, and the World Bank) to reach the goal of primary "Education for All" by 2015. 
comparable pay) in the immediate post-independence period, thus artificially raising the average salaries of those graduates. The result of this work was a substantial increase in bank funding for primary education and a major reduction in that for higher education. Once the bank made that decision, other donors followed. As one USAID official commented to one of us in I993, if the World Bank with all its economists comes to the conclusion that funding should be reduced for higher education and shifted to primary education, we will follow their lead. Indeed USAID funding for Africa fell significantly during this period.

\section{Decline in International Support for Higher Education}

The decline in international development assistance to higher education and the shift in focus to primary education were in a context in which funding for higher education had remained low for some time. As one relatively recent study noted, "For nearly two decades, international development assistance has, with few exceptions . . . viewed the role of post basic education in Sub-Saharan Africa (SSA) with a blind eye. Pushed by conditionalities and pulled by matching fund requirements, African governments have reluctantly followed suit" (World Bank, 2009a, p. I).

Overall external funding for Africa averaged \$103 million annually during I990-I994, then dropped to \$30.8 million a year for 1995-I999. It rose to only $\$ 36.6$ million between 2000 and 2004 in contrast to much higher levels of funding for primary and secondary education. World Bank Sub-Saharan Africa funding for primary and secondary education from I990 to I995 was over \$100 million a year and reached \$2I6 million in I993 (World Bank, 2009a, pp. I-2, 4). Its expenditures on education as a whole increased the following years to $\$ 363$ million in 2004 remaining at that level until 2007 when it went to $\$ 707$ million and then $\$ 720$ million in 2009 . However $90.4 \%$ of that went to primary and secondary education, while only $7.5 \%$ (\$53.2 million) went to tertiary education overall (World Bank, $2009 \mathrm{~b}, \mathrm{p}$. I). From that period to 20I2, bank funding averaged $\$ 55$ million a year to Sub-Saharan Africa tertiary education (World Bank, 20I3, p. 3). The decline in World Bank support to higher education was generally mirrored by other donors.

Currently a few examples on the donor front are encouraging, including a recent World Bank \$200 million project Strengthening Tertiary Education in Africa through Africa Centers of Excellence (World Bank, 20I2). It should get underway in 2014 and focus on several critical areas of higher education including science technology, engineering, mathematics, health, and agriculture. It will include a focus on empowerment of women and will have a regional emphasis with the aim of support- ing five to I5 university centers of excellence selected on a competitive basis. The Carnegie Corporation also has provided substantial funding for higher education in its multi-million dollar programmes in targeted countries focusing on support for graduate training, increasing the quality and number of faculty with $\mathrm{PhDs}$, and fostering research and publications, information technology, and leadership in universities in Ghana, Uganda, and South Africa.

The majority of Sub-Saharan African countries, however, are still plagued by the consequences of budget cuts. The overall pattern of reductions in donor funding exacerbated the consequences of cuts imposed by local governments when they confronted both local and international budget crises. All of these factors had a devastating effect on most of Africa's universities and higher education institutions. Almost every nation suffered from budget cuts, salary freezes, and a moratorium on recruitment that led to reductions in staff while, in most cases, enrollments continued to grow. For most of Sub-Saharan Africa, this period was marked by a deterioration of facilities, loss of research funding, and other difficulties, which had a substantial negative impact on the quality of higher education at a time when the demands on these institutions were increasing.

The decline in state and donor funding is starkly illustrated by the decline in per capita public spending for higher education in Africa which fell from: "US\$6,800 in I980, to US\$I,200 in 2002, and by 2009 averaged just \$98I in 33 low-income SSA countries" (World Bank, 2009 a, Saharan vii). This is a staggering decrease of $82 \%$. While donor funding in general declined in Sub-Saharan Africa over this period, the overall economic news for Sub-Saharan Africa recently has become somewhat brighter. The growth rate of the economy in Sub-Saharan Africa in 2012 rose to $5.3 \%$ and to $6.1 \%$ in 2013 . It is predicted to grow to $6.8 \%$ in 20I4, excluding South Africa (African Economic Outlook, 20I4, p. I). Several countries, including Sierra Leone, Niger, Côte d'Ivoire, and Liberia are growing at faster rates (World Bank, 20I3d, p. 2), in part due to the export of oil and minerals. However, this growth is not likely to be reflected in higher expenditures on higher education given other national priorities and past spending patterns-especially not on graduate education. Furthermore, many of the more recent emphases of the World Bank and other donors are on private/public partnerships and generating other sources of income including remittances from those working abroad, debt relief, and loans guaranteed through various means including the International Development Association (World Bank, 20I3c). Little of this funding is likely to be reflected in increased funding for higher education or graduate education. 


\section{Decline in Overall Quality in Most Higher Education Institutions}

Africa south of the Sahara has a long history of outstanding higher education institutions, as noted earlier. Sawyerr (2004) has pointed out that Makerere University

had built up a substantial research infrastructure whose outputs received international acclaim. In the first years after independence (I962-I970), political stability and the hopes created by independence brought new research initiatives to the university. Of particular note were the East African Institute of Social Research, ... the University Farm at Kabanyoro, the Medical School research programme at Mulago Hospital and the Faculty of Science, especially in Botany, Chemistry, Physics, and Zoology. (p. 239) Unfortunately, Makerere and many other outstanding institutions declined, starting in the I970s. Reversing that decline has become increasingly difficult.

On the one hand, access to information was becoming increasingly available, and universities were beginning to recognise the growing importance of knowledge societies (Drucker, I994, p. 2), which both promised unfettered access to knowledge through information technology and new development opportunities. Still, most African universities suffered from a technological divide that increased the economic gap between the rich and the poor countries of the world (UNESCO, 2005, p. 5). These new technologies and the need to keep up with the developments in information technology in particular, posed new costs and demands on higher education which many countries found difficult, if not impossible, to meet.

The amount and quality of research and publications also declined during this period, almost universally in African universities from a combination of shortage of funds (Mugenda, 2009, p. 25), growing teaching loads, and salaries so low in many systems (including Nigeria) that most faculty members with families needed second jobs to support them. Although South Africa did not suffer from the same salary and funding problems, its faculty research also declined because of the diversion of faculty time to other activities related to the transformation from apartheid higher education after majority rule in I994. That was followed by demands for increased participation by faculty members in committees involved in putting together the large number of mergers of universities and universities and technikons mandated by the Ministry of Education (Moja \& Hayward, 200I).

Teaching, too, generally declined in quality because of the overall increases in class size, increased course loads, elimination of tutorials in many universities, the low level of qualifications of many of the new teachers (Mugenda, 2009, p. 36), and the consequent lack of time for proper preparations by faculty members who were overwhelmed by the high teaching loads and failure of higher education leaders to protect standards as they had in the ig6os and i970s. Other developed and developing nations invested heavily in the expansion of higher education quality and infrastructure (especially information technology) around the world, based on their recognition of the central role of higher education in development; however, African leaders had no similar success in obtaining the funding they needed, and thus the gap between Africa and the rest of the world continued to grow (Gerritsen, 2009). These conditions impacted on both the ability to offer graduate training and, where it existed, limited its quality.

\section{Enrollment Growth}

Another challenge for African higher education was the growing demand for higher education beginning in the ig6os. In 1970, fewer than 200,000 students in Sub-Saharan Africa were pursuing higher education degrees. By 2008 , the total was estimated at 4.8 million (Montanini, 20I3, p. 3). The current estimate of tertiary education enrollment in Sub-Saharan Africa Sahara is Io million students. The surge in enrollment growth coincided with financial pressures on universities due to cuts in aid and in government support, a situation that has only added to their problems. Growth in student numbers occurred primarily at the undergraduate level but inevitably had consequences for graduate education. Our data on enrollment growth in recent years is spotty. Data we gathered from I9 Sub-Saharan African countries (I997-2013) accounted for more than three million of Africa's undergraduate students (about one third of the estimated total). Figures on graduate enrollment from between 1997 and 2007 from ig higher education institutions show a total of I69,275 graduate students studying for master's and PhDs-6.9\% of the total enrollment at that time. The data since that time, though incomplete, from 20I0-20I3 show an increase of graduate students to a total of 294,339 , now $9.3 \%$ of the total enrollment at these institutions, an increase of $73.9 \%$. While this is a substantial increase in graduate student numbers over five year, more that half of it $(56 \%)$ reflects growth in graduate student numbers in South Africa. Of this total of graduate students, approximately $20 \%$ were studying at the $\mathrm{PhD}$ level, with $80 \%$ at the master's level. Of those studying for a PhD in South Africa, 338 were from other Sub-Saharan African countries in 2007-an increase from only 86 in 2000 (ASSAf, 2010, p. 50), a signal of determination and continuing success. 
To put these figures into context it is important to know the completion rate of graduate students. Globally, graduate programmes see a substantial drop-out rate during graduate programmes, and African graduate education suffers from the same problem. The Center for Higher Education Transformation (CHET) has conducted a very interesting and useful study focused on the completion rate for graduate students in Sub-Saharan Africa (CHET, 20I3). The center examined four African universities: the University of Ghana, Makerere University, the University of Cape Town, and Witwatersrand University. Among other aspects, it appraised the productivity of graduate education, which it measured by the percentage of a given cohort of graduate students who finished their degrees. The magnitude of the drop-out is demonstrated by their findings. The "cohort output equivalent" as they called it, was $45 \%$ for Cape Town, 38\% for Ghana, 38\% for Makerere, and 4I\% for Wits. The Center for Higher Education Transformation continued this evaluation for South Africa universities for graduate students who matriculated in 2004-2005, and who had, six years later, achieved their master's or PhD degrees. The percentage of new entrants who graduated in that time period overall (2004-20IO) was 55\%, ranging from a high of $73 \%$ for Rhodes to a low of $14 \%$ for Vaal. This study provides a reminder of the drop-out problem in graduate studies programmes generally and the difficulties of producing master's and $\mathrm{PhD}$ graduates in any country.

\section{Catching Up with the Rest of the World}

Sub-Sarahan Africa's Lag in Research and Graduate Education

In the greater scheme of things, Sub-Saharan higher education is a newcomer on the world stage. It is not to be compared with European higher education, with its ancient history of having evolved from the founding of the legendary universities of Bologna and Paris in the IIth and i2th centuries, and followed by the universities of Oxford (II67), Cambridge (I209), Padua (I222), and Naples (I224) to name a few. Originally conceived as a training forum for theologians, physicians, and civil service administrators, the European university traversed a long evolutionary road to become the modern research university, shaped en route by new and sometimes subversive world views and influences emanating from Europe's succession of cultural, religious, and political epochs such as the Renaissance, the Protestant Reformation, and the Enlightenment. The modern Western university has also been shaped by changes and innovations in the economic system, from the Industrial Revolution to the contemporary Silicon Valley and dot.com revolutions. The Western university, therefore tested by time and matured by experience, is said to be one of a handful of institutions (including the Roman Catholic Church) that have survived more or less intact from the Middle Ages.

In contrast, most universities in Sub-Saharan African countries (excluding Sierra Leone, Ghana, Uganda, and South Africa) were established only after the attainment of political independence from colonial rule, a process that began with Ghana's independence in I957. Only four are older than 65 years: Fourah Bay College, Makerere University, Liberia College, and the University of Cape Town. Most of these institutions began as colleges of universities in their colonial homelands. Fourah Bay College (Sierra Leone) began as a college of the University of Durham; the University College of Rhodesia (Zimbabwe) as a college of the University of Birmingham; and the Universities of Ghana and Ibadan as protégés of the University of London. The same was true of the universities in Francophone countries, where the universities in Dakar, Yaoundé, Abidjan, and Brazzaville, among others, began as campuses of universities in France (Obanya, 2004). Therefore, the new African university was fashioned after the European model, and its vision and mission paralleled that of a European university with little or no accommodation to African realties. Academic courses were structured to provide seamless articulation with postgraduate programmes at Oxford, the Sorbonne, or other prestigious European universities, whose degrees came with more cachét. Consequently, the African university missed the opportunity to indigenise, thereby becoming the primary source of knowledge production and dissemination geared to national development.

The new African university was confronted with other challenges that placed it squarely on the back foot laboring under a handicap. The colonial legacy had left new universities lacking a critical mass of indigenous scholars to staff them, leaving them to rely on expatriate faculty largely from the colonial motherland. Understandably, the early university prioritised the vocational and professional training of teachers, doctors, lawyers, and the like. Mohamedbhai (2008) notes: "During the post-independence period of ig6os through mid-ig80s, African higher education played an important role in providing high-level manpower in areas pertaining to social and economic development."

However, research remained woefully undervalued. Given the low or non-existent industrial base and with agriculture at a subsistence level, there was little or no commercial demand for applied research, and the value and utility of research in national socioeconomic development went unrecognised by either the universities or the political establish- 
ment. The new African university was further handicapped by decades of political instability, authoritarian governance, military coups, and civil wars in many countries throughout the region. Simultaneously, the university struggled against the inevitable decay that resulted from the strategy of "structural adjustment" imposed by the World Bank and its prioritisation of basic education which left higher education virtually abandoned. Among the casualties of all these influences were institutional research, faculty development, and graduate education upon which higher education depends.

Indeed, a recent World Bank (2OI2) project makes that point strongly by admitting: "Africa is at the bottom of almost every knowledge economy indicator. For instance, it contributes with $0.07 \%$ of global patents applications, an indication of the continent's technological leadership. The region has the lowest researcher-to-population ratio in the world with less than Ioo researchers per million inhabitants compared to about 700 in North Africa, 300 in Latin America, and I600 in Central and Eastern Europe" (p. 2). It thus signals a long way to go to create the foundation for high-quality research, graduate education, and knowledge creation.

\section{Africa and the Knowledge Economy}

In the last two decades, Sub-Saharan Africa has witnessed a wave of democratic transformation of previously authoritarian and military regimes in many countries that now embrace elective politics. Democracy as a condition for membership is now enshrined in the constitutions of regional and continental organizations of nation states such as the African Union and the Southern African Development Community. With power now increasingly vested in the electorate, the citizenry has come to hold high expectations for a better lifequality education, accessible health care, liveable housing, adequate service delivery and, above all, job opportunities. These demands and expectations obliged governments to give economic development a high priority.

Indeed, "pro-poor" social and economic development has become the buzz phrase in African intellectual and political discourse. As it happens, the fastest-growing economies in the world today are in Sub-Saharan Africa. According to the African Economic Outlook 2013 published by the African Development Bank, the countries at the top of the list are Sierra Leone (I2.2\%), Chad (I0.2\%), Côte d'Ivoire (8.7\%) and Republic of Congo (8.5\%). However, these high growth rates, derived from the export of commodities like iron ore and diamonds, have not translated into measurable progress in social development.
Indeed, these high-growth countries have among the most dismal rankings on the U.N. Human Development Index, which assesses, inter alia, education, life expectancy, health, poverty, and inequality. Games (2013) concludes that "inclusive growth is not happening at the same pace. This raises issues of governance and the commitment of leaders to invest in a sustainable future" (p. 9). Specifically, the increasing "take" from resources and corporate taxes is not finding its way to funding support for a vibrant academic research environment and a sustainable graduate education programme, both of which are prerequisites for effective and meaningful indigenous knowledge production. According to Sawyyer (2004), "Every society needs to insure the existence of viable indigenous knowledge systems, i.e., local institutions, structures, cadres which, in combination, are able to [generate knowledge] and generally make it usable by local communities. . . . The inadequacy of such systems in Africa is both the cause and effect of the continent's knowledge poverty and deepening material deprivation" (p. 2I4; emphasis ours).

\section{The Current State of Graduate Education in Sub-Saharan Africa}

\section{Overview}

The colonial origins of most of African higher education also meant that graduate education was not considered as an important part of universities at their origin. The view was that, if graduate education was needed, students could travel to the colonial "homeland," meaning France, England, Portugal, or Spain. Indeed, some of that graduate education was provided, especially in areas such as medicine and a few areas of science and technology thought to be useful to the colonial government. But those opportunities were limited. A few fortunate students were also supported for study in the United States or elsewhere if families had the funds to support them, or if they were eligible for support by foreign governments, religious organizations, or donors such as the Ford Foundation. Consequently, as noted earlier, not only were African universities late-comers to higher education in general, but graduate education particularly faced this barrier.

Thus, the current state of graduate education in Sub-Saharan Africa can rightly be described as continuing to be in crisis, a consequence of the deleterious impact of past and present challenges that have faced higher education in the region since the I970s. Even ascertaining the total number of universities in Sub-Saharan Africa is uncertain. Webometrix (2013), the organisation that specialises in ranking universities across the world, lists a total of 542 higher education institutions as of 20I2, but a more recent estimate is about $\mathrm{I}, 500$ public and private 
universities. ${ }^{2}$ The last two decades have witnessed significant growth in numbers, with new universities being launched across the region in response to the mushrooming demand for higher education, fuelled by waves of massification at primary and secondary school levels. Still, demand for university admission continues to exceed capacity even as some governments put pressure-for political reasons-on universities to admit more students than academic staff and infrastructure can reasonably accommodate. The Université Cheikh Anta Diop in Dakar, Senegal, is a case in point. Originally designed for 25,000 students, this university now has an enrolment of 70,000 (IAU, 20I2, p. 25). Despite these developments, the higher education enrolment ratio in Sub-Saharan Africa is reported to be about 5\% (Bloom et al., 2006, p. 3). This ratio is the lowest in the world and only one-fifth the world average of $25 \%$ (World Bank, 20I2, p. 3). Sub-Saharan universities are also experiencing a surge in demand for admission to doctoral studies and graduate programmes-many of questionable quality-which have proliferated in the region in the last few years, albeit from a very low base. The growth in the number of new universities has accentuated the challenge of the shortage of qualified academic staff across the board, which has made it difficult to sustain quality university education even in established universities.

In the South African Development Community (SADC) region alone, according to the most research conducted by South Africa Regional Universities Association (SARUA), doctoral enrolments constitute just I\% of total university enrolments. When South Africa is excluded, the proportion drops to a paltry 0.I7\% for the region (Kotecha et al., 20I2, p. I6). Translated into actual numbers, the research showed that, in 2007 , I0,578 students were enrolled in doctoral programmes; of this number, only 530 were enrolled in regional universities other than South Africa. To give some context, SADC is made up of I5 southern African countries with a total of Io9 publicly funded universities as of 2012, 23 of which are located in South Africa. This pattern represents an increase of some 48 new universities in the region which, in 6I, numbered only 2008 , the youngest being in the Seychelles. For the I9 countries south of the Sahara for which we have data, by 2013, the total number of PhDs students had grown only to $\mathrm{I} 8,872,{ }^{3}$ more than half of which are in South Africa and only 6,050 (32\%) are studying outside of South Africa.

Given South Africa's position as an outlier in these rankings, as well

2. Personal communication with Damtew Teferra, January 2014

3. We compiled these figures based on partial data from Benin, Botswana, Cameroon, Congo, Côte

d'Ivoire, Ethiopia, Ghana, Kenya, Madagascar, Malawi, Mauritius, Mozambique, Namibia, Nigeria, Rwanda, South Africa, Senegal, Tanzania, and Uganda. as its unique political history in the region, it is pertinent to take a closer look at some of the more interesting features of doctoral study in that country. The Academy of Science of South Africa (ASSAf) undertook a comprehensive investigation of doctoral study at South African universities between 2000-2007, and published its findings in The PhD Study (ASSAf, 20IO). The top nine of the country's 23 South African universities were responsible for $83 \%$ of doctoral graduates in 2007 . These also happen to be the older, well-endowed, and previously white institutions located in the largest and wealthiest cities in the country. The situation in the younger institutions situated in rural or semi-urban environments were, in many respects, probably comparable to the status in the rest of the SADC universities.

The situation in East and West Africa has received particular attention from the International Association of Universities (IAU). In an initiative to "examine the changes taking place today in higher education institutions in Sub-Saharan Africa, as part of their overall effort to improve their doctoral programmes and to enhance their research capacity and quality," the IAU (2OI2) conducted an in-depth survey of the state of doctoral studies in six pilot universities selected for regional representation and selected to represent both Francophone and Anglophone institutions. The survey consisted of a preliminary self-assessment questionnaire followed by an exhaustive site visit at each of the participating universities. Six universities participated in the survey, four from West Africa-the University of Douala (Cameroon), the Université de Sciences et Technologies du Benin, the Université Gaston Berger de Saint-Louis (Senegal), and the University of Ilorin (Nigeria), and two from East Africa- the National University of Rwanda, and Kenyatta University (Kenya). The survey spanned 2008-2010. The purposes of the IAU project were: (a) to unpack the context in which the institutions were operating, (b) analyse the nature of doctoral studies, (c) map the characteristics of students and supervisors associated with the doctoral programmes, (d) investigate the key challenges facing the institutions in the organisation, management, and delivery of the doctoral programmes; and (e) identify and analyse key areas of policy reform for the improvement of the delivery of doctoral studies at institutional and national levels.

The participating universities reported a robust upsurge in enrolments in doctoral programmes, from a collective 373 candidates in 2005 to I,454 in 2009 , with two of the universities reporting seemingly massive current enrolments of 467 and 310 doctoral enrolees respectively. However, the universities were generally ill equipped to cope with the rising demand, showing deficiencies on several fronts. 
There was a lack of national policy on or political commitment to research at government level. At the institutional level, infrastructure inadequacies were a cause for concern. Internet connectivity was slow, tenuous, and expensive. Libraries were poorly stocked, and "laboratory equipment and related material [were] in a sorry state and needed considerable upgrading." The universities lacked coherent research policies and strategies, and there was no central coordinating management structure (such as a research office or office of graduate studies) to manage graduate programmes across the university. Absent also were effective management information systems to keep track of a student's progress and to store data on research topics, funding sources, or assigned supervisors. Universities were unable to produce reliable data on the number of students registered for graduate studies, and other discrepancies emerged between the information reported in the questionnaires and the actual situation revealed in site visits. Academic supervision of graduate students was often chaotic and lackadaisical, with "no clear records of study paths and length of study. Some students 'go missing' only to reappear after several months or years. All universities report a lack of tracking mechanisms on who is registered where and who supervises whom" (IAU, 20I0, p. 45).

In summary, the crisis in graduate education in Sub-Saharan Africa is multi-pronged. The national level lacks political commitment to academic research in general and graduate education in particular. The universities are underfunded with consequent (a) dilapidation of infrastructure, (b) underdevelopment in such essential services as the library, Internet connectivity, and management information systems, and (c) a critical shortage of academic staff with intolerable staff-to-student ratios. The institutional level lacks policies, strategies, and leadership directed to research and graduate education. Universities are generally poorly managed, in part due to a lack of institutional autonomy and political interference. Because university heads are politically appointed in the large majority of universities, administrative problems include a lack of internal accountability and collegial cohesion. These and other features of the African university have cultivated a culture and environment that is inimical to successful and effective graduate education.

\section{Staff Shortages}

Tertiary education student enrollments, after remaining relatively stable in the I980s, experienced substantial increases in student numbers thereafter while funding declined. Total student numbers increased by $8.7 \%$ a year from 1990 to over 4 million students in 2008 -almost triple the figure in 1990 (World Bank, 2009, p. xxvi). At that rate the total number of students was projected to be 5.8 million by 2013 . At the same time, many universities were suffering from the brain drain triggered by deteriorating salaries and terms of service, political instability, student unrest, and attractive job opportunities elsewhere. The result was staffing shortages at many universities. David Shinn (2008) has estimated: "About 30,000 Sub-Saharan Africans holding PhDs now have lives outside Africa. Over the last three decades, for example, Kenya has lost more than one third of its professionals. ... More than 3000 doctors have left Ethiopia leaving 900" to serve the population (pp. 2-3), estimated at over 85 million. The effect on higher education has been similarly devastating.

The staff shortages in many African universities have been compounded by the fact that the average age of faculty members is relatively high at many universities since hiring freezes, budget cuts, low salaries, poor working conditions, and a limited pool of new PhDs have hampered the recruitment of new young faculty members. In 2006 , only I\% of faculty members in Malagasy universities were under age 40 , while the average age of the faculty was 56 years with 71\% over age 50 (Ministry of Education, 2006). Although we do not have updated figures for the next seven years, the current economic crisis in Madagascar makes it unlikely that the situation has improved. Like many other universities in Africa, Malagasy universities are finding they have to encourage faculty members to stay on after they reach retirement age. But that is only a short-term solution.

Faculty shortages were made worse by growing public pressure for increased access to higher education. That demand will only grow as the tremendous increase in primary students, resulting from the success of the Education for All efforts, move through primary schools into secondary schools, and seek places in higher education, a process that is just beginning.

Staff shortages have been exacerbated by the brain drain-the loss of qualified faculty members to more attractive job offers in the United States, Canada, Europe, the Gulf, and other African countries with higher salaries and better conditions of service, such as South Africa. Ghana will need a thousand new lecturers over the next few years, according to a Vice Chancellor but is able to hire only 20 or 30 a year-barely keeping up with retirement (Lindow, 2008, p. I). Makerere had a $41 \%$ deficit in its staff; the psychological staff showed a shortage of $60 \%$ in $2004-2005$ (Tettey, 2008). 


\section{The Challenges of Recruitment and Retention}

As we have seen, in the last three decades, Sub-Saharan higher education has experienced phenomenal growth and expansion with a dramatic increase in the number of universities, explosive growth in higher education participation (UNESCO, 20IO), and an escalating demand for graduate education, all fuelled by increasing primary- and secondary-level enrolments. While this growth offers promise for the region's future, it has tended to exacerbate the plethora of challenges that have historically plagued higher education, summed up in a report of the National Association of State Universities and Land Grant Colleges (NASULGC, 2008, p. 4), namely:

critical shortage of quality faculty; limited capacity of governance, leadership, and management; inadequate financial support; inadequate facilities and infrastructures; problems of quality and relevance of teaching and research; limited capacity of research,

knowledge generation, and adaptation capabilities; and problems in meeting increasing demand for equitable access.

The difficulty in recruiting and retaining faculty with senior academic qualifications and research experience - a prerequisite for quality graduate education-represents an existential threat to the region's academic enterprise. Research by NASULGC (p. I) further reveals:

Across Africa and disciplines, on average, only $70 \%$ of the required faculty positions are filled, and in some departments this is only about $30-40 \%$. Not less than $40 \%$ of the faculty members in many universities in Africa are near retirement age, and over 30\% of faculty sent overseas for training fail to return.

In a study conducted in the SADC region, the most frequently reported critical shortages by participating universities were in the areas of science, health sciences, engineering, business, management and law (Butcher et al., 2008; Wilson-Strydom et al., 20I2, p. 30).

Sawyyer (as cited by Butcher et al., 2008, p. 94) sketches an intriguing sequence of developments leading to the low quality of home-grown faculty at today's African universities. He describes three generations of Sub-Saharan home-grown academics. The first generation was educated in the post-independence euphoria of the Ig 60s when the newly established universities were generously funded, and academic careers were highly valued. These graduates took advantage of the plentiful opportunities for graduate fellowships in industrialised countries, and subsequently returned to take up academic careers in their home countries. This was the golden age of the African university, with the universities of Ghana, Ibadan (Nigeria) and Makerere (Uganda)—among others-enjoying inter- national recognition as centers of excellence. However, the I970s saw Africa descend into the doldrums marked by harsh economic conditions resulting in part from poor governance and political conflict. The serious underfunding of higher education triggered what was to be a sustained decline of the African university made up of dismal working conditions coupled with the lack of autonomy and academic freedom. The dilemma was compounded by the structural adjustment programmes of the World Bank and the International Monetary Fund Africa that dictated a shift in funding from higher to primary and secondary education. The African university lost its hard-won prestige and credibility, and many of its brightest and best academics migrated to countries in the North. The best post-secondary students shunned the local institutions and left to study abroad, never to return. Thus, this second generation of African scholars was lost. From the mid-I980s onwards, opportunities to study abroad diminished significantly, and overseas study had become all but inaccessible except for the well-heeled, self-funding student. Students of this period were therefore obliged to complete their studies at the academically degraded home university with little or no credible graduate study programmes. It is this generation that presently populates the African university faculty.

\section{Qualifications Profile of Academic Staff}

On the whole, fewer than $50 \%$ of academic staff at African universities held doctoral degrees in 2009 (Hayward, 20I0, p. 38), with a significant number in some countries holding just a bachelor's degree (Altbach, 20IO, p. 24I). It now appears that the total is even lower today. Our data show an average of $38 \%$ for the Io universities for which we have data; a recent World Bank estimate is less than 20\% (World Bank, 20I2, p. 3). This lack of faculty members with PhDs has had adverse implications for the quality and depth of the instruction provided to undergraduate students, and for the capacity to provide adequate supervision for graduate students.

Some countries and individual universities are worse off than others. In the SADC region, South Africa is an outlier, with 4,694 academic staff with PhD degrees at 23 universities. The region's other I4 countries have 3,747 faculty with doctorates spread over about 90 universities (Kotecha, 20I2, p. 22). Disappointingly, the profile of academic staff qualifications at universities in the region has shown no improvement in two separate surveys conducted by SARUA in 2006 and 2010 (Table I). 
Table 1. Highest Level of Qualification of Academic/Research Staff Members in 2006 and 2010, SADC

\begin{tabular}{|l|c|c|}
\hline Qualification & $\begin{array}{c}\mathbf{2 0 0 6} \\
\%\end{array}$ & $\begin{array}{c}\mathbf{2 0 1 0} \\
\%\end{array}$ \\
\hline Undergraduate (bachelor's) & 18 & 18 \\
\hline Postgraduate below master's & 9 & 9 \\
\hline Master's & 30 & 31 \\
\hline Doctorate & 30 & 28 \\
\hline Other & 13 & 15 \\
\hline
\end{tabular}

Note: Adapted from Wilson-Strydom et al. 2012, p. 28.

According to Altbach (20I0), "It is unlikely that, on balance, the qualifications of academic staff will improve dramatically in the coming period" (p. 24I). Large numbers of teachers will be required to meet the demands of the continuing expansion in enrolments throughout the developing world, and that in turn will bring severe strains to bear on the capacities of these universities to provide advanced training for the under-qualified staff.

Adding to the challenge of staff shortages is the widespread practice of "moonlighting" by academic staff members who are enticed to take on external part-time employment to supplement their relatively meager salaries. Outside work may take the form of consultancy in private projects or teaching in neighboring private colleges (IAU, 20IO, p. 36). By virtue of their qualifications and given the skills shortages in the region, staff members of professorial rank have ready opportunities and are more likely to engage in this practice. The combination of heavy workloads and extramural employment inevitably compromises the availability of these academics for supervision of graduate students.

The "brain drain" or migration of highly qualified African scholars principally to the North, but also to stronger economies within the region such as South Africa, greatly contributes to the shortage of academic staff in Sub-Saharan Africa. According to the International Organization for Migration (IOM) (cited by National Association of State Universities, 2008, p. 9), 23,000 academics and 50,000 middle and senior management personnel leave the continent each year. The brain drain also occurs within countries (Hayward, 20Io, p. 37) with faculty members leaving the academy to take up full-time employment at private colleges, in business, or with non-governmental organizations. Globalisation has facilitated the migration across borders, with academics moving from countries with relatively low salaries and poor working conditions to those with greater resources. Migration is a global phenomenon, with academics from the former Soviet Union migrating to Western Europe, and those from the United Kingdom moving to the USA (Altbach, 2010, p. 238).

For most higher education institutions in Sub-Saharan Africa, maintaining existing graduate programmes has been difficult. The prospects of launching new post-graduate programmes or expanding existing ones is even more challenging. Some universities are maintaining the status quo but are not able to make the kinds of quality improvement needed to provide the graduate training required for a quality postgraduate programme. In the last few years, these problems have been complicated further by the current international economic crisis which is affecting government revenues, university-business partnerships, fund-raising campaigns, and donor contributions to post-graduate education and faculty research. Funding for faculty research has become particularly scarce over the last two decades, hurting faculty productivity and also affecting research opportunities for graduate students-critical to successful completion of their studies.

Many African states recognise the need to expand post-graduate education to meet their development needs, to produce graduates who are competitive in the highly charged international market place, and to create the conditions for their own knowledge economies as engines of their economic growth. As the Minister of Education in Mauritius put it:

We need to relook into our existing infrastructural facilities if we want to attract more foreign students and foreign institutions. The standards of the courses and the qualifications to be dispensed must be of international repute. We must lay more and more emphasis on research, innovation and development. Our institutions should become more creative and dynamic centers of knowledge creation, dissemination and application. It is only in such an enabling environment that we can expect to develop this sector. (Gokhool, 2006, p. IO)

While it is recognised that high-quality higher education, including graduate education, is essential to national economic growth, the ability of governments to fund that level of quality - and especially the higher cost graduate programmes-remains limited, especially in the context of rising demand for access to public undergraduate higher education. Raising funds in other ways, such as increased tuition or fees is also increasingly difficult under the current economic conditions, and most donors continue to shy away from higher education, with a few 
exceptions. As the World Bank (2002) has shown after years of neglect of higher education in Africa, no nation moves into the realm of developing economies without a high-quality higher education system. Another study (Hanushek \& Woessmann, 2007) has demonstrated that the key to economic development is the quality of higher education, not its size, level of student attainment, or enrollments. To attain that quality of higher education, institutions need both to improve their higher education institutions and to develop or expand high-quality graduate programmes. Few African governments have been able to meet that challenge.

\section{Rethinking Graduate Education in Sub-Saharan Africa}

\section{Meeting the Challenge}

One of the ways to begin meeting the challenge posed by the shortage of qualified faculty members in Sub-Saharan Africa must be to find ways to stem the tide of migration of its brightest scholars to wealthier countries in Africa or abroad and to incentivise those already in the diaspora to return, or at least to get involved in other ways in the revitalization of higher education in Africa. Altbach (20I0) points out that academics and scientists who have settled abroad do return to their home countries when working conditions improve. Thus migrant Taiwanese and Korean academics returned to their respective countries when these nations became thriving democracies with vibrant academic institutions, and "a growing number of foreign-educated Chinese are returning home as the universities and working conditions for academics improve" Other migrants from these countries have worked to establish productive networks and to promote knowledge transfer between their adopted countries and their countries of origin. Teferra (20Iо, p. 85) points to the critical role that Chinese, Indian, and Taiwanese entrepreneurs working in Silicon Valley in the United States played in the creation of innovation-based enterprises in the software and electronics sector in their home countries.

Numerous initiatives have been undertaken and organizational structures created at global, regional, and country levels to promote the return, or at least the recruitment into developmental partnerships, of the African expatriates. The International Organization for Migration's "Return of Qualified African Nationals" Programme was in place for I5 years but achieved the repatriation of only 2,000 African nationals. The intellectual diaspora is unlikely to be a significant source of recruitment for African universities as long as the "push factors" that caused them to migrate abroad in the first place continue to prevail in the home countries, including the poor working conditions and absence of an academic ethos at the universities. Expatriate interviewees have cited "bureaucratic red tape, hierarchical structures [authoritarian vice chancellors], and poor infrastructure and facilities," as well as "lack of adequate social services, absence of democracy, and human rights abuses" as some of the reasons for not returning (Mohamoud, 2005). Furthermore, returning academics are not always welcomed with enthusiasm, being sometimes perceived as a threat to position and rank by the home-grown academics.

Lastly, international collaboration with leading universities in the industrialised countries has been suggested as one way to make up for staff shortages. Indeed, there are numerous research collaborations and memoranda of agreement in place between individual African universities and institutions in the North, particularly in the United States and the United Kingdom. These arrangements certainly have their place in the revitalization process, but the asymmetry of power-including the power of resources-between the parties has its downsides. For example, the International Association of Universities (IAU) study found that sponsored research was "driven to a large extent by [the] source of funding and not by strategic priority setting” (IAU, 20IO, p. 44) on the part of the recipient institution. Until the African universities recreate themselves as credible academic institutions, these relationships will remain unequal partnerships. Nonetheless, the number of African countries that can afford to provide incentives is probably limited to a few in Southern Africa plus a handful that have made significant economic progress in the last few years including Ghana, Rwanda, Nigeria, and perhaps Sierra Leone, which has a growth rate over I $2 \%$ and a long tradition of commitment to higher education (Africa Economic Outlook, 20I4, p. 33). Perhaps a few others may also qualify.

\section{New Sources of Funding for Higher Education}

With economic recovery underway in some parts of Africa, a few governments may be able to make greater contributions to higher education; but we expect those increases to be modest in most cases. New nongovernment sources of funding will probably also be modest but with some significant contributions from business, local foundations, and other donors. The ability to charge higher fees is also limited in most cases, in part because the political cost of potential student unrest can be high. Increased donor support can help get new graduate programmes started, but even that is usually only a short-term possibility. Most university budgets have been cut to the bone already; and as we have noted, faculty salaries in general remain low-in fact, too low in many places to attract the best and brightest faculty members. Yet the failure to increase funding for higher education presents a dilemma that threatens to con- 
tinue leaving African states without the qualified graduates they need for national development and without the quality faculty members required at both the undergraduate and graduate levels.

Those universities that do not charge fees need to be able to do so for some of their services. And in many cases where fees are charged, the amount required needs to be increased to cover more of the costs. South Africa has been charging students about one third of the real cost of education for years. It has an excellent loan scheme, one of the few in Africa to be solvent (Moja \& Hayward, 2005), which is available for poor students. Students also pay for food and housing, with most poor students qualifying for subsidies.

Makerere University has pioneered a plan that allows students who did not qualify for admission based on examination scores to do so by paying fees-a plan that has allowed additional numbers of students to attend the university. That additional funding has also helped the university overcome a severe shortfall in funding. Nonetheless, the plan has been criticised for increasing the teaching load of faculty in general. The increase in student numbers has not been offset by an appropriate number of new faculty members. In addition, some less popular areas, such as the sciences, have not been able to generate the same level of additional funding as others and have declined as a result because they have not been able to reward their faculty with supplementary paid teaching. Faculty members have seen a decline in their salaries compared to colleagues in more popular areas (Mayanja, 2009, p. 3).

While the question of student fees is a very political issue in most countries, the reality is that no government can afford to meet the access demands of its citizens and at the same time provide high-quality education, in particular graduate education, for all its qualified students. The State of California in the USA provided free, high-quality higher education to its residents for decades and would be the eighth richest country in the world if it were not a state. Even so, in I970, it could no longer afford free higher education and had to start charging tuition. High-quality post-graduate education in particular, will require some contributions from the students or a significant commitment to scholarships and student loans.

Part of the solution is to try to reduce demand-or at least the level of admissions - to undergraduate university education while encouraging students to go into mid-level studies that provide the vital skills needed in support areas for technicians, nurses, social workers, and business specialists-programmes that require no more than two years of study. Not only is it the case that no nation can afford to have all its secondary graduates go on to university education, but it is also the case that more people are needed with mid-level skills-those provided by community colleges, teacher training institutions, and technical colleges-skill that can be achieved without four-year university degrees. The United States has more community colleges than universities but still has a shortage of mid-level professional workers in IT and such technical areas as laboratory technicians, nurses, and business professionals. Sadly, few African nations are set up to provide this level of education. South Africa is an exception and is also currently embarking on a major effort to establish community colleges (John, 20I3) and to expand technical education. Investments in two-year post-secondary skills training would be very cost effective and should free up some additional funding for higher education.

Increasing the role of university alumni in funding is another possibility. Ghana has been remarkably successful with that approach. Alumni have paid for several building projects at the University of Ghana, for example. Building an alumni base takes time. It requires getting alumni interested in what the university is doing, getting them to participate in some of its activities, and creating a sense of obligation for those who have the funds to provide some support. While the initial steps are time consuming, it can be a very successful process in the long run. Part of the process involves starting to keep track of new graduates from the beginning and keeping them informed about the achievements and needs of their institution after they graduate. As the University of Ghana has shown, it is also worth getting in touch with them later in their careers and encouraging their involvement in the institution while seeking their financial support.

In the long run, non-government sources of funding are essential to enable public universities to have the flexibility to achieve the level of development and high quality needed to develop first-rate graduate programmes. The ability to attract and obtain these additional resources gives universities greater control over their finances and administration. That increased autonomy is essential to efficient operation of graduate programmes and faculty research.

While there are possibilities for additional funding for African higher education, most of them take time to develop. Thus, overall, the funding outlook for higher education in general and graduate education in particular, remains bleak in the short run. We see no solutions that promise "quick fixes" for graduate education. On the other hand, high-quality national or regional graduate programmes are essential for economic growth. Some combination of the strategies noted above will need to be used if such programmes, beyond the few that exist at the present time, are to be established effectively in Sub-Saharan Africa. 


\section{Developing a Culture of Research}

Another area that has suffered over the years is research in spite of early successes in many of the first universities in Sub-Saharan Africa. The decline in research has resulted from a combination of problems: the loss of most research funding, growing teaching loads, few faculty members with PhDs and research training, a failure to recognise the importance of first-rate research as critical to good teaching, as well as a failure to recognise the important role of higher education in solving national problems and fostering national development.

The clearest measure of the low level of research in Sub-Saharan Africa can be seen in the low level of publications by its scholars. Even in relative terms, the numbers of publications for Sub-Saharan Africa are low with the exception of South Africa. The publication output of South Africa was 14,809 during 200I-2004. That is followed by Nigeria with 2,309, Kenya with 2,067, Tanzania with 855, followed by Ethiopia with 767 , Uganda with 734 , and Ghana with 64I. After that, the drop-off is substantial. For comparative purposes with other developing countries during that same period, Singapore had 20,219, South Korea 83,695, Malaysia, 4,729, and Mexico 32,882. Another indication of the decline in publications in Sub-Saharan Africa is that, in the sciences, for example, publications declined by $31 \%$ by 2007 from its peak in 1987 (Tijssen, 2009, pp. 307, 313).

All of this suggests the importance of a major effort to improve research funding for Sub-Saharan Africa and to encourage high-quality faculty research. Success in increasing research quality and output is essential to the development of the high-quality graduate programmes so badly needed in Africa. It also improves the quality of teaching at the undergraduate level. Faculty members who are not themselves researchers will not be able to train high-quality graduate students. Few of them will be able to provide the stimulation, oversight, and training needed to prepare graduate students to carry out high-quality research or to produce the kind of graduate research that is needed for first-rate theses. Producing graduates who are not able to do first-rate research will continue the downward cycle of higher education. Thus, a multipronged effort is required to enhance research among existing faculty members and to build centers of excellence which can provide highquality graduate programmes. A strong research environment will also provide vital opportunities for graduate student involvement in faculty research and enhance their opportunities to serve as research assistants, teaching assistants, science and laboratory assistants, and interns.

Establishing research administration programmes in African universities might also go a long way to help improve the research environment. These programmes can monitor available funding from foundations, private business, and government, encourage funders, assist scholars with their research proposals, and monitor research expenditures. One of the most critical prerequisites of high-quality graduate programmes is first-rate research by faculty members. An effective research administration programme can help make that happen.

\section{Private Higher Education}

Greater involvement of the private sector as a source of potential funding for both public and private higher education can be a powerful additional source of support. Private higher education institutions, especially at the undergraduate level, have proven to be important contributors to higher education systems in many parts of the world. This is especially true where they are overseen by effective quality assurance and accreditation mechanisms. We have also seen that private higher education, especially without on-going accreditation, can lower the quality of higher education-exacerbating problems by producing graduates who do not meet the quality and skills requirements of employers or who do not have the skills to be entrepreneurial (Hayward, 2005). The establishment of private higher education institutions, especially non-profit institutions, can take care of a significant portion of the demand at the undergraduate level as we have seen in a number of countries outside Africa. While few private institutions in Africa today are offering graduate programmes, that is a long-term possibility. We have seen very successful private graduate education programmes in other developing countries. Pakistan is a particularly good example with outstanding graduate programmes at Aga Khan University and the Lahore University of Management Sciences.

In Madagascar currently, for example, public universities are very nervous about the expansion of private higher education institutions and see them as a threat to their long-term existence. That has been part of the impetus for quality improvement in public universities - and it seems to be having a very positive effect in Madagascar. Competition between public and private universities has been an important factor in producing high-quality higher education in the United States. There is no reason that the same should not be true for Africa.

Some excellent private universities in Africa, such as the Catholic University in Antananarivo, are setting high standards. Others are more interested in making a profit than in providing quality education. Distinguishing between not-for-profit and for-profit private tertiary institutions, as many countries do, and providing the former with tax 
and other benefits (such as access to land, duty-free import of education materials, no income tax on profits reinvested in the institution) can have a salutary effect in encouraging non-profit tertiary education and enhancing opportunities for access especially at the undergraduate level.

Catholic University in Antananarivo, which is noted for its academic excellence, also emphasises its ethical and moral expectations of students and staff. Given the current political turmoil in Madagascar, this idealism has had a great appeal to potential students and to the public, with the result that the university is overwhelmed with requests for admission (Rajoelison, 2008). With recent elections, it is hoped that the political turmoil in Madagascar will cease as will its destabilizing effects on public higher education.

One solution to the problem of lack of research output in Sub-Saharan Africa is to give both public and private education institutions access to research funding on a competitive basis as is done in the United States through publicly funded agencies like the National Endowment for the Humanities, the National Science Foundation, and some private foundations. African countries could set up equivalent institutions with or without donor assistance.

Many private higher education institutions, especially in the forprofit sector, argue that they should not have to carry out public service or demonstrate that they make a contribution to national development. For example, in South Africa, some private institutions protested against the Council for Higher Education's (CHE) Criteria 18, which required: "Quality-related arrangements for community engagement are formalised and integrated with those for teaching and learning ... and are adequately resourced and monitored" (CHE, 2004, p. 20). The response, in South Africa and in a number of other countries, has been that, in exchange for the privilege of being allowed to operate a higher education institution, private higher education institutions are required to make a contribution to national and local development. Both public and private institutions are held to that standard. If private institutions were exempted, they would have a financial advantage over public institutions which, in most countries, have service to the nation as part of their mandate.

Overall, with a few exceptions such as those noted above, the role of private higher education institutions in graduate education in developing countries has been limited and, on the whole, unsuccessful. Thus, there are few good alternatives for improving graduate education other than increased government funding and private support for public graduate education.
Regional Graduate Study

The recognition that graduate programmes are a major avenue to enhance Sub-Saharan African economic growth and a key to knowledge creation has sparked the growth of regional graduate centers. Twentythree regional postgraduate programmes were identified in a recent study ranging from the African Centre for Crop Improvement at the University of KwaZulu-Natal in South Africa to a programme focusing on Research Methodology between Jomo Kenyatta University of Agriculture and Technology and the University of Malawi (World Bank, 2009a, Appendix C). Strong graduate programmes provide a vital link between research and teaching and expand opportunities for graduate research. To date, however, these are supported primarily by national governments with limited external support. An exception to that is the Pan-African University established by the African Union and designed to focus on graduate education in targeted areas beginning with five regional campuses in Algeria, Nigeria, South Africa, Kenya, and Cameroun (Woods, Chanie, Padayachee, \& Olsson, 20I2).

One indication of the recognition of the value of regional graduate education is the recent increase in the number of foreign students at the post-graduate level in South Africa. New enrollments in South African master's programmes have grown from $9 \%$ in 2000 to $16 \%$ in 2005 with $70 \%$ coming from other African countries. Half of these were from the Southern African Development Community (SADC) countries. Part of that growth reflects South Africa's generosity to its SADC neighbors by allowing them to pay the same tuition as South African students-a substantial savings on tuition for those foreign students. Master's graduates in public institutions increased by $56 \%$ from 2000 to 2009 while, at the doctoral level, graduates grew from 2000 to 2009 by $67 \%$ (CHET 20I3, p. 2). The largest number of doctoral graduates was from SADC countries with $32 \%$ of the total in 2005 (CHET, 2009, p. I9). The same study shows that by 2009 the private sector was producing a small number of master's graduates (497) and a very small number of PhDs (6). Unfortunately, the situation of South Africa, which is economically better off than most of its neighbors, does not suggest that such subsidies of external master's and $\mathrm{PhD}$ training are likely in many other countries. Other possibilities might be Nigeria, and perhaps Senegal since its reform of doctoral programmes in 2005, and perhaps Kenya, though their ability to support foreign students is limited. A few countries like Senegal have played a regional role as a center for higher education for decades. Others may be able to take on this role as their economies improve. Financing such expansion is a critical question. On the other hand, even if African governments have 
to pay the full cost of such graduate education for their students in other African countries, it would be much cheaper than setting up graduate programmes of equal quality at home.

As noted earlier, while South Africa has shown significant growth in graduate education overall, in most of the rest of Sub-Saharan Africa, the growth of graduate studies has been relatively slow. A study of four universities by CHET (Universities of Ghana, Cape Town, Makerere, and Witwatersrand) shows very low and flat growth at the master's and doctoral levels, averaging a relatively constant head count in Ghana of $8 \%$ master's and $\mathrm{I} \% \mathrm{PhD}$ over three years while Makerere averaged $4 \%$ master's and I\% PhDs over 2008-20I0 (CHET, 20I3). Part of the problem has been the pressure of the growing enrolments of undergraduates which have increased costs for higher education and made it difficult to expand or develop more costly graduate programmes, even at institutions with a long history of a distinguished research culture such as Makerere, Ibadan, and the University of Ghana.

Thus, because of a combination of government neglect of higher education generally outside of South Africa, the pressure to expand undergraduate education, the financial problems confronting higher education overall, and the political turmoil in many parts of Africa, graduate education has continued to be largely ignored in most of Africa throughout this period. One consequence of that neglect has been the movement of large numbers of Africans to overseas universities to obtain their education. By 2010, an estimated 380,000 African students were studying abroad, $6 \%$ of all African students (Marshall, 2013). Only in the early 2000 , other than in South Africa, did attention begin to be focused on the graduate education needs of Africa south of the Sahara and that concern has had limited success to date.

A previous article (Hayward, 20I0), suggested that regional cooperation in graduate higher education might be one interim solution to the problem of low quality in higher education. While we continue to believe that regional cooperation is one of the solutions to the problem of quality, it now appears to be much more difficult than anticipated. Some progress has been made with the Pan-African University, with its commitment to master's and PhD training and research in five academic areas: water and energy; life and earth sciences; space science; basic sciences, technology, and innovation; and governance, humanities, and social sciences. However, the actual process of establishment, operation, governance, and funding is very difficult and complicated by different academic traditions, laws, and expectations. Though the World Bank provided five million dollars in start-up funding, obtaining the needed donor cooperation for the campuses has proven to be espe- cially complex and challenging. In retrospect, the possibility of such cooperation taking place generally in Africa was too idealistic under the present circumstances to be an effective short-term solution to graduate education needs. Donor support is also increasingly hard to find. The African Union is now wrestling with these difficulties in establishing the Pan-African University. There are too many national demands on funding to enable many African leaders to be willing or able to send funds abroad for such a collective effort.

For historical and ideological reasons, South Africa has played a regional role in the SADC countries, which do have an unusual level of cooperation. However, it is South Africa which is subsidizing this effort, with some donor support. For example, the Carnegie Corporation has been supporting master's and PhD training at several South African universities, but other countries are not making similar contributions. Such cooperation is not unknown around the world. In South Asia, India is bearing all the costs of the South Asian University in Delhi, at least at the outset, for the SAARC countries (Afghanistan, Bangladesh, Bhutan, India, Maldives, Nepal, Sri Lanka, and Pakistan). However, both of these are unusual examples following from the unique situations and experiences of these two countries which are not likely to be emulated elsewhere. What seems more likely is that, as the quality of graduate programmes at particular national universities becomes more outstanding, they will attract bright students from neighboring countries who will find a variety of ways to fund their study. In some cases it will be through scholarships from their own governments, in others with their own funds. What seems unlikely in the short run at least, is cooperative government financing schemes, although the Pan-African University may turn out to be an exception, given its unique Africa-wide origin. Nonetheless, we expect to see a more regional focus of graduate education in Sub-Saharan Africa as centers of excellence, such as those in South Africa, are recognised.

Recreating a Culture of Teaching, Learning, and Research

Part of what needs to happen is to recreate the intellectual excitement search for answers, and creativity that existed on many African university campuses in the I960s and I970s-the intellectual community that was decimated by years of crises, economic decline, increasing teaching loads, erosion of pay, and standards of living. To be sure, some of that capacity still exists and there are pockets of great creativity. But on the whole, the conditions for a reemergence of that community need to be put in place to achieve the revival of a culture of research, as well as one of teaching and learning. How can that be done? Part of the 
answer requires recognition by governments, donors, and the public of what needs to be done. As we have noted, part of what is essential is additional funding in almost every case. And also, as we have discussed, such an achievement is extremely difficult in much of Africa. But it is not just funding that is needed. A careful, thoughtful plan to rebuild quality is essential, as is a commitment to quality on the part of faculty and administrators. Among the key needs is to reestablish research capacity among the faculty members and a new commitment to teaching.

In most universities, the establishment of first-rate graduate programmes will also require the recruitment of additional well-trained staff, a reduction of the teaching load to reasonable size (which may require caps on enrollment), adequate remuneration (so that faculty members do not have to take second jobs to survive), and a new commitment of both institutions and faculty members to excellence. New graduate programmes also should be focused on only a few key areas which fit national and regional needs so that the benefits of additional funding will be seen locally. A core of excellence remains at most universities. That might be the starting point for a graduate programme. However, that core has, for the most part, been overworked and underpaid. That situation will need to be rectified. Yet as Szanton and Manyika (2002) note:

Despite the terrible trauma suffered by most of the NLUs [universities south of the Sahara and north of the Limpopo] in recent years, there nevertheless remains within them a core of dedicated scholars, researchers and administrators, as well as bright and energetic junior faculty who are personally committed to serious scholarship and advanced graduate training. (p. 42)

What they need are the conditions, facilities, and the support to create the excellent programmes required. These three factors have been sorely lacking, with the exception of South Africa and a few other isolated cases.

Finding the additional staff needed for high-quality graduate programmes, as noted earlier, is not an easy task. South Africa, with a large number of universities, has managed to do this without the risk of "in-breeding"-having graduates teach at the institution where they studied for their PhD. High-quality programmes need fresh ideas and backgrounds from multiple academic traditions. This is harder in small countries. But "growing your own" can be done well if the right conditions exist. One good example of such success is in Ghana where its staff and its graduate master's and $\mathrm{PhD}$ students have tended to stay in Ghana, giving the government good value for its investment
(Gyekye, 2002, p. I2). Many of the post-graduate students were already employed at the time they received their master's or PhDs, while others felt a commitment to stay and work in Ghana. Gyekye also estimated the cost of study in the United States or United Kingdom to be ten times the cost of study in Ghana (p. 36), comparable to other cost comparisons noted here. Recently, the government has once again begun to focus resources on higher education in Ghana and that is a hopeful sign.

\section{Innovative Post-Graduate Programmes:}

Several innovative and creative post-graduate programmes have been developed in Africa in the last few years, some of which continue at the present time. We discuss four promising examples from Ethiopia, Ghana, Mauritius, and South Africa that might be replicated elsewhere.

\section{The Higher Education Master's in Africa (HEMA)}

A promising innovative, high-quality Africa-wide master's programme was developed in South Africa. It was a cooperative project between the University of the Western Cape (UWC), Makerere University, and the University of Oslo, funded by the Norwegian Agency for Development Cooperation (NORAD). It included students from eight African countries and was designed to strengthen higher education in Africa through building quantitative and qualitative capacity focusing on African higher education and development. It was built around existing programmes at Makerere and UWC, which were linked with the master's programme in Oslo. The programme was supplemented by seminars, research training, close cooperation from advisors, and ties to a multinational research network. The programme was facilitated by the Centre for Higher Education Transformation (CHET) in South Africa.

The students targeted for participation in this programme were those already involved in higher education, those with aspirations to be researchers, administrators, or policymakers, or those involved in higher education in other ways. The emphasis on developing research skills with a focus on rigorous research and verification made this programme particularly promising in a context in which higher education research needs to be reinvigorated, expanded, and significantly enhanced in quality.

Ghana: Problem-Based Learning at the University of Development Studies The University of Development Studies (UDS) was established in I992 in Northern Ghana and has emphasised socio-economic development focusing on community contact in the North, practically oriented pro- 
grammes, problem solving, and student activism (Kaburise, 2003). The programme includes a summer project over three years with students from different disciplines seeking, preparing, and implementing a development project in a rural community in cooperation with local people. These programmes proved to be popular with students, employers, and the communities. Graduates of UDS have been eagerly sought by employers.

The Medical School, which was established in 1996, picked up on the community-based participatory model of the institution and switched its training from the traditional MD programme, in cooperation with the University of Ghana Medical School and the Kwame Nkrumah University of Science and Technology, to a problem-based, student-centered medical curriculum in 2007. Its emphasis has been on training health professionals and doctors to work in disadvantaged communities in rural Ghana.

Similar to the undergraduate programme, the Medical School has focused training on interdisciplinary teams which are sensitive to local customs and needs and which work in collaboration with local populations to improve health care. This work has been in cooperation with the Ghana-Netherlands Health Research and Development Programme and the World Bank. Students start practical work in their first year and participate in community development programmes in specific rural areas over a three-year period in cooperation with the local community. A review of the programme noted that the Medical School is making "good strides" towards the integration of a student-centered, community-based education programme with UDS's existing student-centered development programme. The Medical School is reportedly "putting together a well thought-out plan that will make this community rotation much more meaningful for the community concerned and for the student." This report adds realistically the factor that the program "keep[s] in mind that a bad experience in the community is sure to 'immunise the student forever' against seeking to serve in rural and underserved regions of the country as a future professional" (Ncayiyana, 2009). While the programme is young, it is off to a promising start and builds on a very successful UDS undergraduate model.

Ethiopia: New Post-Graduate Programmes and the Sandwich Model With help from the World Bank (2003), Ethiopia embarked in 20032004 on a major programme to expand access to higher education, including the expansion of graduate programmes with the goal of six thousand graduate students by the end of the project. They planned to add I9 PhD programmes at Addis Ababa University and 59 master's programmes as well as $\mathrm{PhD}$ and master's programmes at several other tertiary institutions (Government of Ethiopia, 2002, p. 48).

As recently as 2008, Abye Tasse, vice president for strategic planning at Addis Ababa University, talked about plans to add 5,000 PhDs in the next ten years (Nordling, 2008). With the expansion of the system to 3I universities and increased student numbers to almost 500,000, the need for large numbers of faculty members with $\mathrm{PhDs}$ is critical.

The effort to increase the number of PhD faculty members in Ethiopia has been underway for a number of years and has established several notable cooperative projects with foreign universities. The most extensive cooperative programme, which is now a quarter-century old, was funded by the Swedish International Development Cooperation Agency (SIDA). It started in 1979 to enhance research and provide capacity building for Ethiopian institutions and to support master's programmes in science.

In 1986 the focus shifted to support for PhD programmes. It included two PhD tracks, both involving study programmes abroad. One was a standard PhD programme abroad at a foreign institution, tied to a specific research project in Ethiopia. The second was a "sandwich programme" with some formal course work abroad. In the sandwich model the students are registered at an Ethiopian university and work with both Ethiopian and Swedish thesis advisors. They spend part of their graduate study abroad taking courses in theory and research methods, and learning the latest in experimental techniques. They conduct fieldwork in Ethiopia where they also write their dissertation. The degree is awarded by the Ethiopian University, either AAU or AUA (Mouton $\&$ Boshoff, 2003, sec. 3.4.2.I). The sandwich model reduces the cost of graduate study considerably, lowers the risk that the student will not return to Ethiopia, and gives the graduate student international experience at a high-quality institution. Such a model could be useful for other African universities.

In spite of these ambitious plans, indications are that these targets are not being met. One report notes that only Ioo $\mathrm{PhDs}$ have been produced in Ethiopia over the last 50 years (Nordling, 2008). These efforts have also suffered from the expansion of the number of universities, the skyrocketing enrolments, and the increasingly heavy teaching load recently required of faculty members. These factors have made higher education faculty positions less attractive. In addition, the recent rapid expansion of undergraduate education resulted in growth that saw the proportion of PhDs in university faculties fall from $28 \%$ in 1998 to $9 \%$ in 2004 (Saint, 2004, p. 35). By 20I2-20I3 the percentage had grown to I0.I\% 
(MoE, 20I3, p. 64). At the same time, faculty workloads have increased tremendously, class size has grown manyfold, research output and quality have declined, and faculty members are feeling increasingly disempowered (Tessema, 2009). Thus, in spite of some innovative efforts to increase the number of PhDs, progressively difficult working conditions coupled with political problems have made university teaching less attractive, sparked a growing brain drain, and made recruitment more difficult. In short, despite the innovative graduate programmes and their early successes, there has been little to show for them.

University-Industry Linkages to Create a Knowledge Economy in Mauritius The fourth case involves a vision of the government and education leaders starting in 2000 to make Mauritius a regional "knowledge hub" by building a state-of-the-art higher education system linked to ICT and the latest technology which would allow the country to serve as a "regional multi-disciplinary center of excellence," attracting foreign investment, foreign institutions, scholars, foreign students and professionals (Gokhool, 2006). Related to this was emphasis on university-industry cooperation. This project represented the government's effort to create a center for knowledge creation, business development, innovation, and high-quality higher education (Hayward, 2006). The plan involved expanding higher education, refocusing the curriculum to meet the needs of knowledge societies, and providing the ICT infrastructure needed to help higher education and business reach the level of quality and technical capacity required to create a regional knowledge hub. The goal of the government was "to transform Mauritius into a Cyber Island in the year 2000 making ICT the fifth pillar of the economy" (Seebaluck, 2008, p. 299). This goal included a major focus on quality improvement in higher education at both the undergraduate and graduate levels, establishing state-of-the-art access to ICT facilities, business parks, and e-education and training.

In the Government Budget Speech for 200I-2002, the case was made as follows:

In our drive to make of Mauritius a Cyber Island, we are not ignoring the need to promote Mauritian entrepreneurship. Our young people are endowed with talent and potential for innovative ideas in ICT. They need to be provided with the necessary support and facilities. The National Computer Board will set up an ICT incubator to promote start- ups. (Seebaluck, 2008, p. 299)

Funding was approved for the project and the ICT Incubation Center was up and running in 2003 with four business customers at the beginning and more to follow (Seebaluck, 2008, p. 299). However, the combination of a change in government, the international financial crisis, the unwillingness of government to provide adequate additional funding for the project, and the programme's failure to attract expected private providers, foreign investors, and foreign students (Mohamedbhai, 2008) crippled it, endangering its long-term success. Local demand for higher education exceeds capacity but government unwillingness or inability to provide adequate funding is making the dream of a knowledge hub less and less likely to be fulfilled. A recent change in government may bring about renewed success for this programme. Mauritius as a regional knowledge hub (TEC, 20I2) remains a major goal of the government.

As these four cases demonstrate, efforts to improve the quality of higher education and foster strong graduate programmes are extremely difficult. Not only are they hampered by financial difficulties, but they are often limited or derailed, as we have seen in two of these cases, by changes in the parties in power and a lack of political will on the part of those in power. While there are some notable successes, especially in South Africa, the problems remain daunting for most tertiary institutions south of the Sahara, and their ability to establish high-quality higher education systems-and especially graduate programmes-is limited. Nonetheless, these examples show what can be done with focused graduate programmes.

\section{Implications for the Future of Graduate Programmes in Sub-Saharan Africa}

While the overall status of post-graduate education in Sub-Saharan Africa, other than in South Africa, is not strong at present, it still shows a number of bright spots as we have seen. These include experiments with different types of graduate programmes, variations of the American model of classes and thesis-writing, regional cooperative graduate programmes, sandwich master's and PhD programmes, and several other innovative efforts. It seems likely that the process of creating new high-quality graduate programmes will in itself prove creative and foster some new approaches appropriate to the economic, political, and cultural conditions of Sub-Saharan Africa.

It seems to us that a number of suggestions follow from this review of graduate education in Africa south of the Sahara. First, a high priority for most universities should be expanded faculty PhD training, locally, regionally, and internationally with target graduate institutions in mind. Very few African universities have enough PhD faculty members in critical areas to launch or expand major graduate programmes. Given the impending retirement of large numbers of faculty members 
in most of Africa, achieving an expanded body of PhD holders is critical if institutions are to maintain current quality levels in undergraduate programmes, improve quality, and pave the way for new and expanded graduate programmes.

Second, a high priority must be given to reestablishing a culture of high-quality research and, with it, establishing high standards and expectations for the products of that research. There is no shortage of problems that need to be tackled by scholars, whether it is policy research in economics, education, science, or other areas. But this will not be a simple task given the neglect of research, the limited number of faculty members conversant with the latest research methods, or the ability to write good research questions and proposals. Nonetheless, the core of talent and experience does exist, and African universities now have access through the Internet to tremendous academic resources including the latest findings in any field. Yet such research needs to be strongly supported and encouraged-a requirement that demands new funding for faculty research, reduced teaching loads for faculty members with major research projects, and recognition of their achievements when they make major findings. It probably also requires that universities encourage research at the undergraduate level (in a targeted manner, given the "massification" of the systems in much of Africa) to get students thinking creatively at an early stage in their academic development and to help them develop a passion for problem solving.

Third, there need to be major concerted efforts nationally, regionally, and internationally to expand and insure adequate financial support for graduate education in Sub-Saharan Africa. This is one of the biggest challenges. The production of poor-quality graduates will only prolong the crisis. In Ethiopia the government allocated less than \$I, 000 for the $\mathrm{PhD}$ and about $\$ 250$ for master's training in 2013 (personal communication, Damtew Teferra, January 20I4). Even with the most dedicated teachers and mentors, that level of support will not produce the high quality needed.

A commendable note is the international support for such efforts, including the 2008 Africa U.S. Higher Education Collaboration Initiative: Empowering African Higher Education for Africa's Transformation, the long-running financial assistance from the Swedish International Development Agency (SIDA) which has included joint doctoral and other graduate programmes since I975 (Lundgren, 2013, pp. 28-30), support for graduate education by the Carnegie Corporation, and the new World Bank Centers of Excellence Programme. Still, such efforts are few. It seems clear that graduate programmes will have to be financed primarily by African governments with help from local donors, businesses, and the students themselves.

Fourth, the major focus must be on increased quality at every level-in new faculty members, in more PhD training opportunities for current faculty members, in an upgraded curriculum that meets international standards, in high-quality facilities for teaching and research, and in higher expectations of excellence from both students and faculty members. Encouraging steps in that direction have been taken over the last decade in the expansion of quality assurance and accreditation (Hayward, 2006). More recently, with support from the Association of African Universities, UNESCO, the Inter-University Council of East Africa, the African and Malagasy Council for Higher Education and others, the efforts at quality assurance and accreditation have been expanded further (Shabani, 2013). Nonetheless, the actual efforts to build high-quality graduate programmes still rests with individual institutions, their faculty members, and the governments, donors, private institutions, and citizens that support them.

\section{Conclusions}

Has African graduate education improved over the last five years? Are regional graduate programmes gaining the support they need to flourish? Are regional graduate programmes making a contribution to the quality of graduate studies in Sub-Saharan Africa? With a few exceptions, including South Africa, Ghana, and perhaps Kenya and Uganda, graduate programmes have not improved markedly over the last five years. What we saw as the promise of regional graduate education has, to some extent made contributions though that has been limited primarily to Southern Africa and funded by South Africa without cooperative government support from outside or much donor assistance. We do see an important future role for regional graduate education, and we hope the Pan-African University turns out to be part of that success. For the most part, we expect national universities to become regional centers of excellence by virtue of the quality of their own graduate programmes, with graduate study at these universities funded by individuals or through scholarships, rather than as cooperative efforts of governments or donors, though we applaud the new World Bank programme to establish centers of excellence and hope for their success. The experience in South Africa is encouraging, and we anticipate that it will be replicated in other regional centers, perhaps in Senegal, Kenya, Ghana, and Nigeria, or perhaps fostered through the Pan-African University.

The key goal for the future of higher education in Sub-Saharan Africa should be to focus on maintaining and expanding high-quality post- 
graduate education nationally. Those African states benefiting from current economic growth should focus some of their new financial gains on improving higher education and, where possible, expanding or establishing high-quality graduate programmes in key areas. Critical to establishing more high-quality graduate programmes, and improving some of those already in existence, will be the revival and expansion of the high-quality research that has been carried out in the past, carried out with new eyes and fresh approaches, but looking at today's critical problems and issues. That research will help foster the innovation needed to establish new cultures of research and graduate teaching on those campuses able to create the conditions to foster them. These centers will attract the brightest minds in Africa, the best teachers, and public-minded academics to support first-rate, post-graduate programmes that will be the equal of programmes anywhere in the world.

Such successes will not come easily-not without major investments in higher education by those governments that recognise the need and potential benefits of high-quality graduate programmes and have the funding to support them, from faculty members who make a commitment to high-quality research and teaching, from students who understand that they must pay for some part of their post-graduate education (or find donors willing to do so) and have the undergraduate training that will prepare them for high-quality research and teaching, and from contributing foreign governments, donors, and international organizations like the World Bank that must listen carefully to the voices of Africa and harmonise their goals with those of educators committed to transformation. Such commitments will help create the conditions for the kinds of changes essential to establishing a number of additional outstanding post-graduate programmes in Africa-programmes that will build on existing examples of excellence and on those universities that are willing and able to create the environment needed to produce first-class research, graduate teaching, and service.

\section{References}

Academy of Science of South Africa (ASSAf). (2010). The PhD study: An evidence-based study on how to meet the demands for high-level skills in an emerging economy. Sandton, South Africa: ASSAf.

Africa Economic Outlook 2013-Special Theme: Structural transformation and nature resources. (2013). African Development Bank publication. http://www.undp.org/content/dam/rba/docs/ Reports/African\%20Economic\%20Outlook\%202013\%20En.pdf. DOI: http://dx.doi.org /10.1787/aeo-2013-en.

Altbach, P.G. (20I0). The academic profession: The realities of devel- oping countries. In P. G. Altbach (Ed.), Leadership for world-class universities-Challenges for Developing Countries. Boston, Massachusetts, USA: Center for International Higher Education, Boston College.

Bloom, D., Canning, D., \& Chan, K. (2006). Higher education and economic development in Africa. Washington DC: World Bank Human Development Sector Africa Region.

Brock-Utne, B. (n.d., circa 2002). Formulating higher education policies in Africa: The pressure from external forces and the neoliberal agenda. Oslo, Norway: Institute for Educational Research.

Butcher, N., et al. (2008). Cross-national higher education performance indicators: Progress report on analysis of the data of selected countries. Cape Town, Africa: Centre for Higher Education Transformation (CHET).

Butcher N., Wilson-Strydom, M., Hoosen, S., MacDonald, C., Moore, A., \& Barnes, L. (2008). A profile of higher education in the region. in P. Kotecha (Ed.)., Towards a Common Future: Higher Education in the SADC Region-Research Findings from Four SARUA Studies. Johannesburg, South Africa: (Wits) Southern African Universities Regional Universities (SARUA).

CHET. Centre for Higher Education Transformation. (2009). Crossnational higher education performance indicators: Progress report on analysis of the data of selected countries. Cape Town, Africa: CHET.

CHET. Center for Higher Education Transformation. (2013). High-level knowledge production: CHET data profiles of four universities. Pretoria, South Africa: CHET.

Council on Higher Education. (2004). Criteria for institutional audits. Pretoria, South Africa: Higher Education Quality Committee.

Drucker, P. (1994). Knowledge work and knowledge society: The social transformation of this century. Cambridge, Massachusetts, USA: Harvard University Press.

Games, D. (20I3, August I2). High African growth rates distort the real development picture. Business Day (South Africa), p. 9.

Gerritsen, J. (2009, March 22). Africa: Fears for the continent's oncegreat universities. University World News. Retrieved on March 9, 20I4, from www.universityworldnews.com.

Gokhool, D. (2006). Address by the minister of education and human resources. At the presentation of the Report of the Sectoral Committee on Knowledge Hub, 29 Nov., 2006, Cyber Tower, Ebene.

Government of Ethiopia. (2002). Ethiopia educational sector development program, July 23, 2003. Addis Ababa, Ethiopia: Ministry of Education. 
Gyekye, K. (2002). A vision of postgraduate education in Ghana. Accra, Ghana: National Council for Tertiary Education.

Hanushek, E. A., \& Woessmann, L. (2007). The role of quality in economic growth. World Bank Policy Research Working Paper, No. 4I22. Washington, DC: World Bank.

Hayward, F. M. (2006). Quality assurance and accreditation of higher education in Africa. Paper presented at the Conference on Higher Education Reform in Francophone Africa: Understanding the Keys of Success, June I3-15, 2006. Ouagadougou, Burkina Faso. Available from http://web.worldbank.org/WBSITE/EXTERNAL/ TOPICS/EXTEDUCATION/o,,contentMDK:20976237 menuP K:6I7592 pagePK:I48956 piPK:216618 theSitePK:282386,00. html.

Hayward, F. M. (20I0). Graduate education in Sub-Saharan Africa. In D. Teferra \& H. Greijn (Eds.), Higher education and globalisation: Challenges, threats, and opportunities for Africa (pp. 33-49). Maastricht, The Netherlands: Maastricht University/Boston, Massachusetts, USA: Boston College.

Hayward, F. M., \& Rasoanampoizina, H. (2007, Winter). Planning for higher education change in Madagascar. International Higher Education, No. 46, I8-20.

IAU. International Association of Universities. (20II). Changing nature of doctoral studies in Sub-Saharan Africa: Challenges and policy development opportunities at six universities in Sub-Saharan Africa. Paris, France: International Association of Universities.

John, V. (20I4, January I6). Blade launches white paper to meet needs of "neets." Mail and Guardian. Retrieved in January 20I4 from C:1 Users $\backslash$ OwnerAppData/Local/Temp/Low/I055TG5W.htm.

Kaburise, J. (2003). New variations on the African development university: The UDS experience with developing an alternative approach to tertiary education. Paper presented at the regional training conference on improving tertiary education in Sub-Saharan Africa: Things that work! Accra, Ghana: World Bank.

Kotecha, P., Steyn, A.G.W., \& Vermeulen, P. (20I2). The status quo of doctoral education in the SADC region. In P. Kotecha (Ed.), Doctoral education: Renewing the academy. SARUA Leadership Dialogue Series, Vol. 4, no. I. Johannesburg, South Africa: (Wits) Southern African Universities Regional Universities (SARUA).

Lindow, M. (2008, December 3). African universities face a looming shortage of PhDs. Chronicle of Higher Education. Retrieved on December 3, 2008, from http://chronicle.com/daily/2008/II/77I8n.htm.

Lundgren, I. (20I3). Support to research training within Swedish devel- opment approach. IAU Horizons, 19(2), 28-30.

Marshall, J. (20I3). Africa: International mobility of African students: Report." University World News Global Edition, Issue 279. Retrieved July 25, 2013, from http://www.universityworldnews.com/article. php?story $=201307052$.

Mayanja, M. (2009). The Makerere University lessons in privatisation: Affirmative action for science. The Nordic African Institute, Norway. Retrieved on May 10, 2009, from http://www.nordicafricainstitute.se/publications/news/archives/o23mayanja/index. $\mathrm{xml}$ ? Language $=\mathrm{sv} \&$ Language.

Mohamedbhai, G. (2008). Mauritius. In D. Teferra \& J. Knight (Eds.), Higher education in Africa: The international dimension (pp. 262302). Accra, Ghana: Association of African Universities.

Mohamoud, A. A. (2005). Reversing the brain drain in Africa: Harnessing the intellectual capital of the diaspora for knowledge in Africa. Amsterdam: SAHAN/NUFFIC. Retrieved on July 24, 2013 from http:// www.diaspora-centre.org/DOCS/Reversingthebraind.pdf.

Moja, T., \& Hayward, F. M. (2005). The changing face of redress in South African higher education: I990-2005. Journal of Higher Education in Africa, 3(3), 3I-56.

Montanini, M. (2013). Supporting tertiary education, enhancing economic development: Strategies for effective higher education funding in Sub-Saharan Africa. ISPI Working Paper, No. 49. Silver Springs, Maryland, USA. Retrieved on February 22, 2014, from http:// www.ifs.se/IFS/Documents/Conferences/ISPI_TertiaryEducation_AFRICA_2OI3.pdf.

Mouton, J., \& Boshoff, N. (2003). The Federal Democratic Republic of Ethiopia. Paris: UNESCO.

Mugenda, O. M. (2009). Higher education in Kenya: Challenges and opportunities. Paper presented at the African Higher Education Cooperative Meetings, March 20, 2009.

National Association of State Universities and Land Grant Colleges. (2008). Challenges facing higher education in Africa \& lessons from experience: A synthesis report for the Africa-U.S. higher education initiative. Washington, DC: Africa-U.S. Higher Education Initiative.

Ncayiyana, D. (2009). Report on the working visit to the School of Medicine and Health Sciences University for Development Studies, Tamale, Ghana. Personal communication.

Nordling, L. (2008). Growing apace in Africa: Ethiopia has a plan to produce thousands of $\mathrm{PhDs}$, to teach and to spur on economic development. The Guardian. Retrieved in July 2010 from www. guardian.co.uk/education/2008/may/13/highereducation.inter- 
nationaleducationnews.

Obanya, P. (2004). The dilemma of education in Africa. London, England: UNESCO, Heinemann Educational Books.

Psacharopoulos, G., \& Patrinos, H. A. (2004). Returns to investment in education: A further update. Education Economics, 12(2): III-I34.

Rajoelison, G. (2008). Rector, Institut Catholique de Madagascar (2008). Interviewed by Fred M. Hayward, November I9, 2008, Antananarivo, Madagascar.

Saint, W. (2004). Higher education in Ethiopia: The vision and its challenges. JHEA/RESA, 1(3), 83-II3.

Sawyerr, A. (2004). African universities and the challenge of research capacity development. JHEA/RESA, 2(I) 213-242.

Seebaluck, R. K. (2008). ICT business incubation: Evidence from Mauritius. In H. Etzkowitz \& M. Roest (Eds.), Transforming university-industry-government relations in Ethiopia (pp. I-24). Malmö, Sweden: International Organization for Knowledge Economy and Enterprise Development (IKED).

Shabani, J. (2013, Fall). Quality regimes in Africa: Reality and aspirations. International Higher Education, No. 73, I6-I8.

Shinn, D. H. (2008). African migration and the brain drain. Paper presented at the Institute for African studies and Slovenia Global Action, June 20, 2008. Retrieved on January 22, 2009, from http:// sites.google.com/site/davidhshinn/Home/african-migration-andthe-brain-drain.

Szanton, D. L., \& Manyika, S. (2002). PhD programs in African universities: Current status and future prospects. A report to the Rockefeller Foundation. Berkeley, California: The Institute of International Studies and Center for African Studies University of California.

Tertiary Education Commission (20I2) TEC: Annual report 2012. Mauritius: Tertiary Education Commission.

Teferra, D. (2010). Higher education and globalisation: Challenges, threats, and opportunities for Africa. Maastruc

Teferra, D., \& Greijn, H. (Eds.) (2010). Higher education and globalisation: Challenges, threats and opportunities for Africa (pp. 33-49). Maastricht, The Netherlands: Maastricht University/Boston, Massachusetts, USA: Boston College.

Teferra, D., \& Altbach, P. (Eds.). (2003). African higher education: An international reference handbook. Bloomington, Indiana, USA: Indiana University Press.

Tessema, K. (2009). The unfolding trends and consequences of expanding higher education in Ethiopia: Massive universities, massive challenges. Higher Education Quarterly, 63(I) 29-45.
Tettey, W. (2008). Comparative analysis of next generation of academics indicators. Calgary, Alberta, Canada: University of Calgary. Presented at the Leaders' Forum in Accra November 2008, and in World University News, April 5, 2009, No. 26.

Tijssen, R. (2007). Africa's contribution to the worldwide research literatures: New analytical perspectives, trends, and performance indicators. Scientometrics, 71(2), 303-327.

UNESCO. (2005). Toward knowledge societies. UNESCO World Report. Paris: UNESCO Publishing.

UNESCO. (20I0). Trends in tertiary education: Sub-Saharan Africa. UNESCO Institute of Statistics. UIS Fact Sheet, December 2010. No. IO.

Webometrix. (2013). Webometrics, Africa: Ranking web of universities. Retrieved on October 30, 2013, from http://www.webometrics:info/ en/Ranking_africa.

Wilson-Strydom, M., \& Fongwa, S. N. (20I2). Profiling the SADC public higher education landscape. In P. Kotecha (Ed.), A profile of higher education in Southern Africa. Wits (Johannesburg): Southern African Regional Universities Association (SARUA).

Woods, D., Chanie, P., Padayachee, A., \& Olsson, A. (20I2). Case study on the Pan-African University. OEDC, Programme on Innovation, Higher Education and Research for Development. Personal copy; document not publicly available.

World Bank. (I988). Education in Sub-Saharan Africa: Policies for adjustment, revitalization, and expansion. Washington DC: World Bank.

World Bank. (2002). Constructing knowledge societies: New challenges for tertiary education. Washington DC: World Bank.

World Bank. (2003a). Higher education development for Ethiopia: Pursuing the vision-A World Bank sector study. Washington, DC: World Bank

World Bank (2003b). Implementation completion report: Republic of Senegal. Washington, DC: World Bank.

World Bank, (2009a). Accelerating catch-up: Tertiary education for growth in Sub-Saharan Africa. Washington, DC: World Bank.

World Bank. (2009b). Education lending in FY 2009. Washington, DC: World Bank. Retrieved on August 30, 20I3, from http://wib.worldbank.org/WBSITE/EXTERNAL/TOPICS/EXTE.

World Bank. (20I2). Strengthening tertiary education in Africa through Africa centers of excellence. Washington, DC: World Bank.

World Bank. (20I3a). Tertiary education (higher education). Washington, DC: World Bank. Retrieved on August 30, 2013, from http://web.worldbank.org/WBSITE/EXTERNAL/TOPICS/ 
EXTEDUCATION/O,content.

World Bank. (2013b). Africa overview. Retrieved on August 30, 2013, from http://www.worldbank.org/en/region/afr/overview.

World Bank. (20I3c). New ways to finance development in Sub-Saharan Africa. Retrieved on October I4, 20I3, from http:econ.worldbank. org/WBSITE/EXTERNAL/EXTDEC/O,contentMDK:2I6785Io-p.

World Bank. (2013d). As Africa's new wealth grows, poverty must come down. News. Retrieved on October 29, 2013, from http://www. worldbank.org/en/news/feature/2013/04/15/as-africa-s-n.

\section{The Regionalisation, Internationalisation, and Globalisation of African Higher Education}

\author{
Chika Sehoole and Hans de Wit
}

\section{Abstract}

The landscape of international higher education has been changing since the turn of the 2Ist century. The globalisation of our societies and economies implies a changing role of the higher education institutions. Accompanying the challenges associated with development, especially in developing countries, are initiatives championing regionalisation as a locus of development. This article positions the debate on the relationships among globalisation, regionalisation, and internationalisation in the context of Africa and its sub-continent, showing that, although these concepts have emerged at different times and contexts, they are still related. Using case studies of two regional political and economic organisations and their higher education counterparts, this article shows that regionalisation is not a new phenomenon but has been part of and has been used in the post-colonial era to serve new social, economic, political, and development purposes in the current period.

about the authors: chika sehoole is an Associate Professor and Head of the Department of Education Management and Policy Studies at the University of Pretoria, South Africa. He holds a PhD from the University of the Witwatersrand, Johannesburg. He is the current chair of the Board of the African Network for the Internationalisation of Education (ANIE). Address queries to him at Chika. Sehoole@up.ac.za. HANS DE wIT is director of the Centre for Higher Education Internationalisation at the Università Cattolica del Sacro Cuore in Milan, Italy, and professor of the Internationalisation of Higher Education at the Amsterdam University of Applied Sciences in the Netherlands. He is Founding Editor of the Journal of Studies in International Education and Co-Editor of the SAGE Handbook on International Higher Education. He is a Research Associate at the Nelson Mandela Metropolitan University in Port Elizabeth, South Africa. Address queries to him at j.w.m.de.wit@hva.nl. Both authors were Fulbright Scholars in the New Century Scholarship Programme, Higher Education in the 2Ist Century, 2005-2006. 